\title{
Presurgical localization of infected avascular bone segments in chronic complicated posttraumatic osteomyelitis in the lower extremity using dual-tracer PET/CT
}

\author{
Albert Christersson $^{1 *}$ (D), Sune Larsson ${ }^{1}$ and Jens Sörensen ${ }^{2}$
}

\begin{abstract}
Background: Localizing and removing the infected sequestrum in long-standing trauma-related chronic osteomyelitis remains a clinical challenge. PET/CT with 18F-fluorodeoxyglucose (FDG-PET) has a high sensitivity for chronic osteomyelitis and 18F-sodium-fluoride PET/CT (NaF-PET) has a high specificity for identifying non-viable bone. Combining both, high signal on FDG-PET in the bone without signal on NaF-PET could potentially guide surgery to become more precise with curative intent.

Eight patients with long-standing (average 22 years) posttraumatic $(n=7)$ or postoperative $(n=1)$ chronic osteomyelitis in the lower extremity and with multiple futile attempts for curative surgery were recruited in this prospective pilot study. FDG-PET and NaF-PET were performed within a week in between using standard scanning protocols. The most likely location of the culprit sequestrum was identified and was surgically removed. Based on perioperative tissue cultures, antibiotics were given for 6-8 months. Dual-tracer (FDG- and NaF-PET/CT) was performed again after 12 months to rule out persisting signs of infection.

Results: A likely culprit sequestrum could preoperatively be identified by dual-tracer PET in all eight cases and in four cases an additional sequestrum was identified at a location with no clinical sign of infection. The infected necrotic tissue was removed during surgery. Follow-up dual-tracer PET revealed no signs of persistent infection. All patients recovered with no clinical signs of recurrence for a follow-up of mean 4.5 (SD 1.3) years.
\end{abstract}

Conclusions: Dual-tracer PET/CT with FDG and NaF allows successful precise surgery with curative intent in patients with long-standing complicated posttraumatic chronic osteomyelitis with severely deranged anatomy.

Keywords: Chronic osteomyelitis, FDG-PET/CT, NaF-PET/CT, Surgical treatment, Preoperative planning

\section{Background}

Infections following operative fixation of skeletal fractures, so-called fracture-related infections (FRI) [1] can be diagnosed by several imaging modalities. CT has low sensitivity and specificity but depicts bone structures, such as sequestrum, involucrum, and cloacae. MRI is able to identify involvement of the soft tissue, bone marrow, and joints, but postoperative scarring and oedema may result in false positive diagnosis, and artifacts from metal implants can prevent

\footnotetext{
* Correspondence: albert.christersson@akademiska.se

${ }^{1}$ Department of Orthopaedics, Institution of Surgical Sciences, Uppsala

University, 75185 Uppsala, Sweden

Full list of author information is available at the end of the article
}

correct evaluation. MRI may also overestimate the extent of the infection due to its high sensitivity. Since CT and MRI mainly provide morphological information, they are often difficult to assess in peripheral skeleton when the anatomy is deranged after previous injury and therefore often combined with nuclear imaging modalities to get functional properties of the bone. Among these, white blood cell (WBC) scintigraphy or antigranulocyte antibody scintigraphy combined with SPECT/CT or 18F-fluorodeoxyglucose (FDG) PET/CT has the highest diagnostic accuracy [2-5]. WBC scintigraphy can also be used shortly after surgery with high accuracy [6]. PET is a technique that measures molecular properties of tissues using specific radiopharmaceuticals in tracer amount. 
18F-fluorodeoxyglucose (FDG) PET/CT is commonly used for imaging in evaluation of malignancies, but is also very sensitive for osteomyelitis due to high accumulation of the tracer in activated leukocytes [7]. Both FDG-PET/CT and MRI have a high and comparable sensitivity for qualitative detection of chronic osteomyelitis. MRI is recommended in unifocal infections, but FDG-PET/CT is preferable in widespread or multifocal cases [8]. The specificity for FDG-PET/ CT, as well as MRI, is low because it detects all kinds of inflammation involving metabolically active cells including anabolic processes during healing $[7,9,10]$. An important advantage for FDG-PET/CT compared with other nuclear imaging modalities is the improved spatial resolution, which makes it easier to localize increased uptake relative to the anatomy. In patients with long-standing posttraumatic chronic osteomyelitis (PTO), where the fracture already has healed and the metal implant has been removed, the clinical history with recurrent pain and fistulation is often sufficient for making the right diagnosis, and in these cases, the higher precision in PET/CT outweighs the problem with lower specificity.

One of the most notorious forms of FRI is a long-standing PTO, which is characterized by persistent infection in non-viable bone segments. PTO is difficult to cure, unless radical resection of necrotic bone can be achieved. Even though FDG-PET/CT detects the distribution of the osteomyelitis with high precision, this information is often not enough for a satisfactory preoperative planning. Assuming that the recurrent infection after systemic antibiotic therapy is caused by surviving bacteria in poorly perfused necrotic bone with low or no accumulation of antibiotics, the important issue preoperatively is not to localize the extension of the osteomyelitis in the bone but to localize the affected necrotic bone. CT, MRI, and FDG-PET/CT are all helpful but are limited regarding true location and distribution of the necrotic tissue. 18F-natrium-fluoride (NaF) is a highly bone-specific tracer, accumulating in the apatite in proportion to the rate of perfusion, mineralization, and bone formation [11]. NaF-PET/CT is increasingly used for visualizing the viability of the bone [12]. The higher precision of NaF-PET, compared to gamma-camera scintigraphy, is potentially helpful when planning a limited and precise resection of the bone, which does not threaten the integrity of the bone. The aim of this study was to examine the potential use of a dual-tracer PET/CT to localize the infected necrotic bone in patients with PTO in the lower extremity by first identifying the focal accumulation of activated inflammatory cells capable of migrating to the site inside the bone with FDG-PET/CT and then localizing the necrotic bone inside the inflammation with NaF-PET/ CT. Our hypothesis was that a limited but precise surgical intervention based on a dual-tracer PET/CT could be both curative and result in low morbidity.

\section{Methods}

This prospective case series consisted of eight male patients with a mean age of 52 (SD 11) years treated for chronic long bone osteomyelitis at the University Hospital of Uppsala, a tertiary referral center, between February 2010 and January 2016. Their history was basically similar, with chronic osteomyelitis after open high-energy fracture in the lower extremity in seven patients, and after ankle arthrodesis in one patient. The mean duration of chronic osteomyelitis was 22 (SD 13) years. All of the fractures were healed, and none of the patients had remaining osteosynthesis material when presented at our clinic. They had previously unsuccessfully been treated with one or more surgical revisions and antibiotics (Table 1).

The study was approved by the Ethical Committee of Uppsala University (Dnr 2015/146), and written informed consent was obtained from all patients according to the ethical guidelines of the Helsinki Declaration. All patients were preoperatively examined with FDG-PET/CT and NaF-PET/CT. All scans were performed with a GE Discovery ST16 hybrid PET/CT (Waukesha, ML) with routine clinical protocols. After at least $6 \mathrm{~h}$ fasting, FDG was injected intravenously $1 \mathrm{~h}$ before imaging $(3 \mathrm{MBq} / \mathrm{kg})$ and emission was acquired for $3 \mathrm{~min}$ per $15.7 \mathrm{~cm}$ bed position. $\mathrm{NaF}$ was injected at a dose of $2 \mathrm{MBq} / \mathrm{kg} 1 \mathrm{~h}$ before imaging with emission acquisition $2 \mathrm{~min}$ per bed position. CT without contrast enhancement was used for attenuation correction and was also reconstructed with a sharp bone-specific filter for visualization of anatomy. PET images were reconstructed with all relevant corrections using standard clinical protocols. FDG-PET and NaF-PET were performed at two different days to avoid interference between the tracers, and the images were fused with the simultaneously acquired CT for precise anatomic orientation of the uptake. The uptake on FDG-PET and NaF-PET were carefully compared to each other and a demarcated high uptake on FDG-PET in an area with low or absent uptake on NaF-PET inside the bone, as seen on CT, indicated inflammation in necrotic bone and was considered to be a sequestrum harboring infection. Standard uptake values (SUV) were recorded as max SUV in the FDG culprit lesion, as max SUV in nearest viable bone with reactive $\mathrm{NaF}$ uptake, and as SUV mean in a corresponding circular region with a 2-cm diameter in the contralateral leg.

Five (5/8) patients with signs of active infection (redness and swelling) were treated with adequate antibiotics for at least 4 weeks prior to and throughout the PET examinations based on previous cultures to reduce the area on FDG-PET affected by the infection, assuming that imaging under ongoing antibiotic treatment would minimize the area of infection for easier identification of the infected sequestrum. The remaining three (3/8) patients had no signs of acute infection and were therefore not treated with antibiotics prior to or during 
Table 1 Characteristics of eight patients with posttraumatic $(n=7)$ or postoperative $(n=1)$ chronic osteomyelitis

\begin{tabular}{|c|c|c|c|c|c|c|c|c|c|c|}
\hline Sex & $\begin{array}{l}\text { Age } \\
\text { (year) }\end{array}$ & $\begin{array}{l}\text { Affected } \\
\text { limb }\end{array}$ & Cause & $\begin{array}{l}\text { Primary } \\
\text { treatment }\end{array}$ & $\begin{array}{l}\text { Duration } \\
\text { (year) }\end{array}$ & $\begin{array}{l}\text { Soft } \\
\text { tissue }\end{array}$ & $\begin{array}{l}\text { Sinus } \\
\text { tract }\end{array}$ & Culture & $\begin{array}{l}\text { Previous } \\
\text { surgeries }(n)^{\mathrm{a}}\end{array}$ & $\begin{array}{l}\text { Coverage } \\
\text { with flap }\end{array}$ \\
\hline Male & 56 & Femur $\mathrm{dx}$ & $\begin{array}{l}\text { Traffic } \\
\text { accident }\end{array}$ & $\begin{array}{l}\text { Intramed nail, } \\
\text { removed }\end{array}$ & 37 & Good & No & $\begin{array}{l}\text { Staff Aureus, } \\
\text { Propionibacterium }\end{array}$ & 2 & No \\
\hline Male & 28 & Tibia sin & $\begin{array}{l}\text { Bomb } \\
\text { explosion }\end{array}$ & $\begin{array}{l}\text { Conservative } \\
\text { treatment }\end{array}$ & 20 & Poor & $\begin{array}{l}\text { Yes, } \\
\text { single }\end{array}$ & $\begin{array}{l}\text { Escherichia coli, Klebsiella } \\
\text { oxytoca }\end{array}$ & $?$ & Yes \\
\hline Male & 57 & Tibia sin & $\begin{array}{l}\text { Traffic } \\
\text { accident }\end{array}$ & $\begin{array}{l}\text { External } \\
\text { fixation }\end{array}$ & 38 & Poor & $\begin{array}{l}\text { Yes, } \\
\text { single }\end{array}$ & Staph Aureus & 1 & Yes \\
\hline Male & 53 & Femur $\mathrm{dx}$ & $\begin{array}{l}\text { Bomb } \\
\text { explosion }\end{array}$ & $\begin{array}{l}\text { Conservative } \\
\text { treatment }\end{array}$ & 22 & $\begin{array}{l}\text { Very } \\
\text { poor }\end{array}$ & $\begin{array}{l}\text { Yes, } \\
\text { multiple }\end{array}$ & $\begin{array}{l}\text { Proteus mirabilis } \\
\text { Pseudomonas aeruginosa }\end{array}$ & 4 & Yes \\
\hline Male & 49 & Tibia dx & $\begin{array}{l}\text { Traffic } \\
\text { accident }\end{array}$ & $\begin{array}{l}\text { External } \\
\text { fixation }\end{array}$ & 12 & Poor & $\begin{array}{l}\text { Yes, } \\
\text { single }\end{array}$ & $\begin{array}{l}\text { Pseudomonas aeruginosa } \\
\text { Propionibacterium }\end{array}$ & 1 & Yes \\
\hline Male & 58 & $\begin{array}{l}\text { Ankle } \\
\text { arthrodesis }\end{array}$ & $\begin{array}{l}\text { Rheumatoid } \\
\text { arthritis }\end{array}$ & $\begin{array}{l}\text { Screw fixation, } \\
\text { removed }\end{array}$ & 13 & Poor & $\begin{array}{l}\text { Yes, } \\
\text { single }\end{array}$ & Pseudomonas aeruginosa & 5 & Yes \\
\hline Male & 55 & Tibia $d x$ & $\begin{array}{l}\text { Traffic } \\
\text { accident }\end{array}$ & $\begin{array}{l}\text { Plate fixation, } \\
\text { removed }\end{array}$ & 2 & Poor & $\begin{array}{l}\text { Yes, } \\
\text { single }\end{array}$ & $\begin{array}{l}\text { Clostridium, } \\
\text { Propionibacterium }\end{array}$ & 1 & Yes \\
\hline Male & 64 & Femur sin & $\begin{array}{l}\text { Traffic } \\
\text { accident }\end{array}$ & $\begin{array}{l}\text { Intramed nail, } \\
\text { removed }\end{array}$ & 33 & $\begin{array}{l}\text { Very } \\
\text { poor }\end{array}$ & $\begin{array}{l}\text { Yes, } \\
\text { single }\end{array}$ & $\begin{array}{l}\text { Serratia, } \\
\text { Staph Epidermidis }\end{array}$ & 7 & Yes \\
\hline
\end{tabular}

${ }^{a}$ Number of documented failed previous surgical interventions intended to address the infection. Other surgical procedures are not included

the PET examinations. All antibiotics were withdrawn 4 weeks preoperatively to make cultures more reliable. For localizing the potential sequestrum, the images from FDG-PET and NaF-PET were examined simultaneously in a parallel manner in axial, coronal, and sagittal sections. Following a thorough preoperative planning, all patients were operated with resection of the presumed necrotic bone. The skin incision in seven (7/8) patients included excision of a sinus tract and the surrounding affected skin, thereby facilitating the access to the bone. The preoperatively identified bone fragments were excised, and the bone cavity was curettaged and thoroughly irrigated. Multiple tissue cultures were taken for confirmation of the diagnosis. Local antibiotic (calcium sulphate (Rapid Cure ${ }^{\circ}$ ) with Vancomycin) came onto the market in 2014 and was used in the last two patients. The integrity of the bone was preserved in all cases and no stabilization with osteosynthesis was needed. All but one patient needed a concomitant coverage with a soft tissue flap. The patients were allowed to full weight bear after the operation. Postoperatively, the patients were given antibiotics intravenously for 1 week, and based on the perioperative tissue cultures (Table 1), they were given antibiotics orally for 6-8 months. FDG-PET/CT and NaF-PET/CT were repeated 12 months after the operation, i.e., at least 4 months after withdrawal of antibiotics. Absence of uptake on FDG-PET at 12 months and absence of wounds and local symptoms in the extremity was considered to be a curative successful treatment.

\section{Results}

In all eight (8/8) preoperative dual-tracer PET/CT, at least one small intraosseous area with high uptake on
FDG-PET and absent uptake on NaF-PET was localized, which were assumed to be the sequestrum (Fig. 1). Median FDG SUVmax was $5.8 \mathrm{~g} / \mathrm{ml}$ (range 2.4-11.4) and the ratio of hotspot/contralateral region 14.4 (range 3.128.5). In four patients, a secondary area with an additional sequestrum was found, separated from the major infection, and located where we primarily had no suspicion of infection. Typically, NaF uptake was highly elevated in the bone adjacent to the sequestrum. Median $\mathrm{NaF}$ SUVmax was $14.5 \mathrm{~g} / \mathrm{ml}$ (range 2.6-47.9) and hotspot/contralateral ratio 12.9 (range 3.3-43.6). The lowest NaF SUV ("coldspot") at the site of the FDG hotspot was median 5.2 (range 2.2-11.8), which was 4.1 (range 1.7-9.6) times higher than contralateral uptake, but also 3.5 (range 3.1-4.9) times lower than the NaF hotspot. SUVmax from FDG and NaF hotspots correlated (Spearman rho $=0.82, p<0.05)$. Perioperative tissue cultures were positive in all eight patients, confirming the diagnosis of PTO. Twelve months after the operation, seven (7/8) patients had complete disappearance of the preoperatively detected increase in FDG-PET uptake. The remaining patient had on the preoperative dual-tracer PET/CT, besides the most obvious area of necrotic tissue inside the bone, an additional small area of increased FDG-PET uptake localized in the soft tissue a few centimeters away from the bone. This area had no uptake on the NaF-PET. This finding was preoperatively overlooked, and it was still present on the postoperative dual-tracer PET/CT 12 months postoperatively. When this area was surgically explored, we found a granuloma with a piece of encapsulated textile from the primary open injury. All eight patients recovered clinically after surgery and are still free from wounds and antibiotics at the time of writing (4.5 (SD 1.3) years after surgery). 


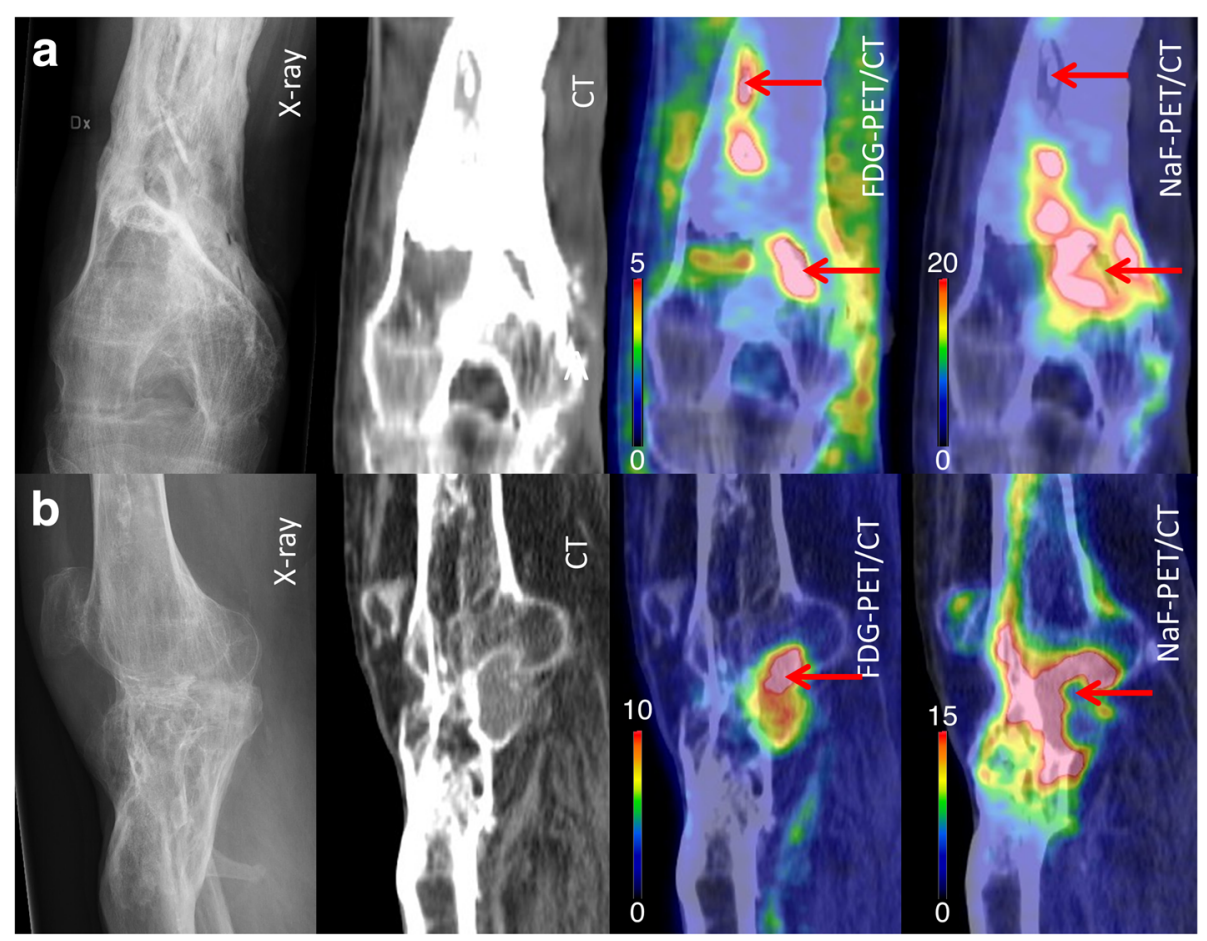

Fig. 1 Preoperative images (X-ray, CT, FDG-PET/CT, and NaF-PET/CT) of chronic osteomyelitis in distal femur in two different patients. The arrows point at bone segments with high uptake on FDG-PET/CT ("hot spots") and low uptake on NaF-PET/CT ("cold spots"). The findings are best visualized in coronal views in patient (a), where two sequestra were found, and in sagital views in patient (b), where one sequestrum was found

\section{Discussion}

This is, to the best of our knowledge, the first paper to describe the combined use of FDG- and NaF-PET in the preoperative planning of long-standing chronic osteomyelitis after trauma. Preoperative FDG-PET in patients with PTO without clinical signs of present acute infection (in $5 / 8$ patients achieved by on-going antibiotic therapy) localized the distribution of the chronic infection as "hot spots." In a few cases, FDG-PET disclosed increased uptake in adjacent bone parts initially not suspected to be affected, such as extensions in direct contact with the major infection but also detached areas away from the major infection. NaF-PET localized necrotic bone as "cold spots," which, in combination with high uptake on FDG-PET, revealed the precise location of the sequestra. A meticulous preoperative planning made it possible to get an adequate access to the infections. The operations with free soft tissue flaps in seven $(7 / 8)$ of the patients contributed to the successful treatment of the infections, but since chronic osteomyelitis cannot be cured without resection of all infected necrotic bone, cure had not been possible with soft tissue coverage alone.

The two tracers used represent distinctly different biological entities. FDG is taken up by a multitude of different cell types involved in inflammation, infection, and bone remodeling, including not only activated leucocytes but also activated fibroblasts. FDG uptake is typically found in healing fractures and bone undergoing remodeling, potentially inducing false positive findings in the setting of localizing infection. $\mathrm{NaF}$, on the other hand, is specifically accumulated in the matrix surrounding activated osteoblasts and free mineral adjacent to perfused tissue [13]. The uptake of $\mathrm{NaF}$ is always elevated in healing bone and anabolic bone remodeling.

The high uptake of FDG in poorly perfused necrotic bone is remarkable. This seems to indicate a constant and rapid migration of leucocytes and other inflammatory cells into the epicenter of the infection leading to an accumulation of FDG in or around the sequestrum. Neutrophils move at a speed of approximately $20 \mu \mathrm{m} /$ min when exposed to specific chemoattractants [14]. Theoretically, white blood cells containing FDG can migrate a maximum of $1.2 \mathrm{~mm}$ during the $1 \mathrm{~h}$ time span from injection of FDG to scanning. The absent or very low uptake of $\mathrm{NaF}$ in the necrotic bone suggests that the diffusion distance of fluoride ions is reduced or that binding to the mineral is repelled by a biological mechanism, i.e., bacterial biofilm [15]. The hypoperfused core of a necrotic bony sequestrum harboring bacteria is therefore less accessible for fluoride ions, resulting in a "cold spot" in the NaF-PET images. This is probably also the rationale for the poor penetrance of antibiotics into the core of the sequestrum. Localizing a cold spot on NaF-PET in an area of a "hot spot" on FDG-PET was 
essential for making a limited but still precise resection of the bone tissue, not endangering the integrity of the bone. As shown here, NaF uptake adjacent to the FDG hot spot can be substantial and $\mathrm{NaF}$ uptake was never zero at the epicenter of the FDG hot spot. If the sequestrum is small there will be "spill-in" of activity into the sequestral region, but a relative $\mathrm{NaF}$ cold spot could always be seen.

A preoperative planning based on FDG-PET alone had resulted in more extensive bone exposure and resection since perioperative assessment of bone viability is a recognized difficult issue. The pursuit of being radical in excising the necrotic bone, and perioperatively only relying on the viability of the bone (i.e., signs of bleeding), increases the risk for removing too much bone, potentially leading to bone instability and a need for fracture fixation, which results in postoperative morbidity. Alternatively, the infection recurs if not all necrotic bone is extirpated. The addition of NaF-PET to FDG-PET seems to improve the accuracy, and we found it essential for a successful outcome in seven (7/8) operations. The dual-tracer PET was very helpful to localize and demarcate the sequestrum in these patients. In addition, in four $(4 / 8)$ of these cases, the dual-tracer PET localized an additional sequestrum. This information was crucial for curative surgical treatment. In one (1/8) patient, with a small unifocal osteomyelitis, the extra information provided by the NaF-PET did not change the surgical procedure, and in this patient, a good result had probably been achieved with FDG-PET alone.

The interpretation of the dual PET is time-consuming and has a learning curve, which makes it user-dependent. A good postoperative outcome relies on a thorough preoperative planning including positioning of the patient, surgical approach, and location for entrance into the bone based on the dual-tracer PET/CT.

A limitation of the study is the short follow-up time. A chronic osteomyelitis can remain inside the bone for many years without any clinical symptoms and recur later. A negative FDG-PET after 12 months, and the absence of clinical symptoms during a few subsequent years, increases the probability of cure, but leaves no absolute guarantee [16].

It is also a limitation that the study has no control group, and no comparison to more commonly used imaging techniques. It is possible that the same good result could have been achieved after preoperative evaluation with CT, MRI, or hybrid imaging nuclear modalities like WBC scintigraphy or antigranulocyte antibody scintigraphy with SPECT/CT. Early dynamic $18 \mathrm{~F}-\mathrm{NaF}$ potentially has the ability to both differentiate infected tissue from healthy tissue and localize necrotic bone [17]. Indeed, if a bone, affected with unifocal PTO, does not have a severely deranged anatomy, CT, or MRI can be sufficient for diagnosis and preoperative planning. It is our experience that dual-tracer PET/CT might have its greatest potential in complicated longstanding posttraumatic cases with severely deranged anatomy when CT and MRI are unable to demonstrate the number and true localization of sequestra.

\section{Conclusions}

Dual-tracer PET/CT with FDG and NaF provides information about the location of the infected sequestra in patients with complicated long-standing posttraumatic chronic osteomyelitis with severely deranged anatomy, which allows successful precise surgery with curative intent.

\section{Ethical approval and consent to participate}

The study was approved by the Ethical Committee of Uppsala University (Dnr 2015/146). All procedures performed in the study were in accordance with the ethical guidelines of the 1964 Helsinki Declaration and its later amendments. Written informed consent was obtained from all individual participants included in the study.

\section{Funding}

This research received no specific grant from any funding agency in the public, commercial, or not-for-profit sectors.

Availability of data and materials

Please contact the author for data request.

\section{Authors' contributions}

AC, SL, and JS participated in the planning and design of the studies and wrote the manuscript. AC made the operations and patient follow-ups. JS made the evaluations of PET. All authors read and approved the final manuscript.

\section{Consent for publication}

All patients included gave written informed consent that their data could be used for scientific purposes.

\section{Competing interests}

The authors declare that they have no competing interests.

\section{Publisher's Note}

Springer Nature remains neutral with regard to jurisdictional claims in published maps and institutional affiliations.

\section{Author details}

'Department of Orthopaedics, Institution of Surgical Sciences, Uppsala University, 75185 Uppsala, Sweden. ${ }^{2}$ Department of Nuclear medicine and PET, Institution of Surgical Sciences, Uppsala University, 75185 Uppsala, Sweden.

Received: 26 April 2018 Accepted: 9 July 2018

Published online: 21 July 2018

\section{References}

1. Metsemakers WJ, Morgenstern M, McNally MA, Moriarty TF, McFadyen I, Scarborough $\mathrm{M}$, et al. Fracture-related infection: a consensus on definition from an international expert group. Injury. 2018;49(3):505-10.

2. Glaudemans AW, de Vries EF, Vermeulen LE, Slart RH, Dierckx RA, Signore A. A large retrospective single-centre study to define the best image acquisition protocols and interpretation criteria for white blood cell scintigraphy with (9) (9) mTc-HMPAO-labelled leucocytes in musculoskeletal infections. Eur J Nucl Med Mol Imaging. 2013;40(11):1760-9.

3. Horger M, Eschmann SM, Pfannenberg C, Storek D, Dammann F, Vonthein $\mathrm{R}$, et al. The value of SPET/CT in chronic osteomyelitis. Eur J Nucl Med Mol Imaging. 2003;30(12):1665-73. 
4. Govaert GA, FF IJ, McNally M, McNally E, Reininga IH, Glaudemans AW. Accuracy of diagnostic imaging modalities for peripheral post-traumatic osteomyelitis--a systematic review of the recent literature. Eur J Nucl Med Mol Imaging. 2017:44(8):1393-407.

5. Wang GL, Zhao K, Liu ZF, Dong MJ, Yang SY. A meta-analysis of fluorodeoxyglucose-positron emission tomography versus scintigraphy in the evaluation of suspected osteomyelitis. Nucl Med Commun. 2011;32(12):1134-42.

6. Govaert GAM, Bosch P, FFA IJ, Glauche J, Jutte PC, Lemans JVC, et al. High diagnostic accuracy of white blood cell scintigraphy for on-going infections: results of a large retrospective single-center study. Injury. 2018;49(6):1085-90.

7. Wenter V, Muller JP, Albert NL, Lehner S, Fendler WP, Bartenstein P, et al. The diagnostic value of [(18) F] FDG PET for the detection of chronic osteomyelitis and implant-associated infection. Eur J Nucl Med Mol Imaging. 2016;43(4):749-61.

8. Demirev A, Weijers R, Geurts J, Mottaghy F, Walenkamp G, Brans B. Comparison of [18 F] FDG PET/CT and MRI in the diagnosis of active osteomyelitis. Skelet Radiol. 2014;43(5):665-72.

9. Hartmann A, Eid K, Dora C, Trentz O, von Schulthess GK, Stumpe KD Diagnostic value of 18F-FDG PET/CT in trauma patients with suspected chronic osteomyelitis. Eur J Nucl Med Mol Imaging. 2007;34(5):704-14.

10. Kaim A, Ledermann HP, Bongartz G, Messmer P, Muller-Brand J, Steinbrich W. Chronic post-traumatic osteomyelitis of the lower extremity: comparison of magnetic resonance imaging and combined bone scintigraphy/ immunoscintigraphy with radiolabelled monoclonal antigranulocyte antibodies. Skelet Radiol. 2000;29(7):378-86.

11. Sorensen J, Ullmark G, Langstrom B, Nilsson O. Rapid bone and blood flow formation in impacted morselized allografts: positron emission tomography (PET) studies on allografts in 5 femoral component revisions of total hip arthroplasty. Acta Orthop Scand. 2003;74(6):633-43.

12. Brenner W, Vernon C, Conrad EU, Eary JF. Assessment of the metabolic activity of bone grafts with (18) F-fluoride PET. Eur J Nucl Med Mol Imaging. 2004;31(9):1291-8.

13. Irkle A, Vesey AT, Lewis DY, Skepper JN, Bird JL, Dweck MR, et al. Identifying active vascular microcalcification by (18) F-sodium fluoride positron emission tomography. Nat Commun 2015;6:7495.

14. Hoang AN, Jones CN, Dimisko L, Hamza B, Martel J, Kojic N, et al. Measuring neutrophil speed and directionality during chemotaxis, directly from a droplet of whole blood. Technology (Singap World Sci). 2013;1(1):49.

15. Gristina AG, Oga M, Webb LX, Hobgood CD. Adherent bacterial colonization in the pathogenesis of osteomyelitis. Science. 1985;228(4702):990-3.

16. Zhuang H, Duarte PS, Pourdehand M, Shnier D, Alavi A. Exclusion of chronic osteomyelitis with F-18 fluorodeoxyglucose positron emission tomographic imaging. Clin Nucl Med. 2000;25(4):281-4.

17. Freesmeyer M, Stecker FF, Schierz JH, Hofmann GO, Winkens T. First experience with early dynamic (18) F-NaF-PET/CT in patients with chronic osteomyelitis. Ann Nucl Med. 2014;28(4):314-21.

\section{Submit your manuscript to a SpringerOpen ${ }^{\circ}$ journal and benefit from:}

- Convenient online submission

- Rigorous peer review

- Open access: articles freely available online

- High visibility within the field

- Retaining the copyright to your article

Submit your next manuscript at $\boldsymbol{\nabla}$ springeropen.com 